\title{
Presentación
}

doi: $10.18543 /$ ced-54-2016pp17-23

Hemos celebrado los 30 años de la adhesión de España a lo que entonces eran las Comunidades Europeas. En su conjunto, y a pesar de la crisis del euro, han sido los mejores años de nuestra historia moderna desde la batalla de Trafalgar.

Pero para mis alumnos en la Facultad de Ciencias Económicas de la Universidad Complutense de Madrid, no está tan claro que haya sido así. Para ellos pesan más los años de la crisis, desde el 2009, que los anteriores.

Para mi generación, el proceso de construcción de la Unión Europea ha sido el de un proceso continuo, con fases de ralentización y de aceleración, en el que las crisis jugaban un papel de catalizador de nuevos avances. Y así se ha acuñado el mantra al que se recurre con frecuencia en Bruselas, de que la UE necesita crisis para progresar y que siempre sale reforzada de ellas.

Pero mis alumnos, la joven generación de europeos, no tienen esta visión porque no tienen una perspectiva larga de la historia. Y ciertamente es dudoso que puedan creer que el cocktail de problemas al que se ha enfrentado la UE en este verano del 2015, le permitan salir reforzada de su múltiple crisis como siempre ha ocurrido en el pasado.

Y puede que tengan razón. Forzoso es constatar que algunos de los más importantes elementos que componen la actual UE están bajo una grave amenaza de desaparición. La crisis del euro no se resuelve, a pesar del acuerdo de última hora con Grecia; la crisis de los refugiados que se ha agravado este verano y ante la cual la respuesta europea ha sido, con excepciones, simplemente vergonzosa, no va a desaparecer; y es posible que el Reino Unido abandone la UE.

Así, dos de los grandes activos de la UE, el euro y la libre circulación de personas, están en cuestión. Y el abandono de algún país importante como el Reino Unido plantea la cuestión de la reversibilidad del proceso hacia «una unión cada vez más estrecha» como dicen los Tratados, precisamente porque algunos países no desean que sea cada vez más estrecha. Ser miembro de la UE podría ya no ser algo adquirido para siempre, y eso debilitaría inevitablemente la dimensión política del proyecto.

Hay que ser conscientes que el control de las fronteras y la movilidad de las personas afectarán a las cuestiones relacionadas con los mercados del 
trabajo y los sistemas de bienestar social. Y de momento hemos visto como los 28 Estados miembros no son capaces de superar sus agrias discusiones y elaborar una respuesta efectiva a sus problemas comunes.

Cada vez son más las voces que se preguntan por la pervivencia de la unión monetaria y del euro concebido como un instrumento al servicio de una prosperidad compartida. Habrá que escucharlas porque es evidente que el euro no ha conseguido muchos de los objetivos que justificaron su creación, y no se puede defender la permanencia en el euro simplemente por los costes que tendría la ruptura.

$\mathrm{Al}$ acabar este triste verano para la UE, una gran parte de sus economías siguen sumidas en una depresión crónica con altos niveles de desempleo y situaciones financieras insostenibles. La implosión de Oriente Medio ha catapultado hacia la apacible Europa cientos de miles de desesperados demandantes de asilo. Y el cambio en el escenario político que esas crisis han inducido, con la emergencia de partidos populistas y anti-UE por la derecha y por la izquierda, ha tenido su última manifestación en la elección de un euroescéptico para dirigir el partido laborista en el Reino Unido.

La crisis de los refugiados y la del euro tendrán una gran influencia en el resultado del referéndum que debe tener lugar en el Reino Unido en el 2016 o el 2017. Hasta ahora yo habría apostado por la victoria de los partidarios de permanecer en la UE. Pero la crisis inmigratoria va a pesar en el argumento más potente que tienen los partidarios del Brexit, es decir que mientras el UK sea miembro de la UE no va poder controlar los flujos migratorios. Y si el precio a pagar es que el UK, que ya no está ni en el euro ni en Schengen, pueda también tener un opting out para la libre circulación de las personas dentro del mercado único, entonces quizás su permanencia empiece a ser demasiado distorsionadora del proyecto común.

Tampoco va a ser muy entusiasmaste para los británicos seguir formando parte de un proyecto que parece agrietarse. Y si finalmente decidieran salir, el sentimiento de crisis de la UE se agravaría porque se acabaría la creencia de que los Estados que adhieren lo hacen para siempre, abriendo la puerta a nuevas defecciones.

Pero lo que pueda ocurrir con el UK, siendo muy importante, no es la más urgente de las preocupaciones que asedian a la fortaleza Europa. Estas son el euro y el control de las fronteras. $\mathrm{Y}$ en ambos casos las agrias discusiones de este verano muestran que no tenemos una respuesta común para hacerles frente de forma efectiva.

La crisis de los refugiados, porque hay que llamarles así y no emigrantes, ya ha puesto en cuestión los acuerdos que parecían solidos sobre la apertura de las fronteras. En los últimos días, después de una generosa apertura decidida por la canciller Merkel, algo que quedará en su honor, Alemania ha vuelto a imponer controles en su frontera con Austria, ésta lo ha he- 
cho con la que tiene con Hungría y ésta trabaja febrilmente para construir un nuevo muro en su frontera con Serbia.

Merkel y Hollande pueden oficiar conjuntamente en Estrasburgo, pero también en materia de asilo los dos países han discrepado abierta y estrepitosamente. Las bases de la política de asilo europea no funcionan ante la nueva realidad en Oriente Medio, pero no se ve muy bien en qué puede consistir una nueva que evite la división este-oeste entre los países europeos.

En su discurso en Estrasburgo del pasado 9 de septiembre, el Presidente Juncker presentó su plan para distribuir 120.000 demandantes de asilo entre los países europeos. Un plan que no está a la altura de la actual crisis ni de la que está por venir. Casi 3.000 muertos en nuestras costas en lo que va de año, y 4,5 millones de sirios desplazados fuera de su país buscando quien les acoja, son cifras que ilustran la magnitud del drama al que Europa tendrá que hacer frente.

La crisis de los refugiados ha situado por un momento en un segundo plano a la crisis del euro. Pero eso no quiere decir que esta haya perdido gravedad. Los problemas del euro no han desaparecido ni se han resuelto, a pesar del acuerdo para que Grecia reciba un tercer plan de ayuda. Por el contrario, la nueva dosis de austeridad que acompaña este acuerdo puede agravar su situación y hacer que el euro se parezca cada vez más para algunos países como una trampa de la que no se puede salir.

A pesar de todos sus problemas, los griegos parecen convencidos de que salir del euro les acarrearía una crisis financiera y económica tan grave que es mejor seguir en él, a pesar de que parece que solo se les propone una austeridad sin fin. Pero tampoco los países acreedores, especialmente Alemania, Holanda y Finlandia, están satisfechos, porque temen que el euro acabe generando un sistema de trasferencias fiscales permanentes hacia los Estados del sur de Europa. Y sus opiniones públicas no están en absoluto dispuestas a aceptar una situación que no estaba en el programa del euro, pero que es lo que ocurre en todas las uniones monetarias estables que existen en el mundo.

Cada vez es más evidente que la concepción de la moneda única que ha impuesto Alemania y que ha prevalecido en la forma de hacer frente a la crisis griega, es insoportable e inaceptable para el sur de Europa. Incluso para Francia, como explica bien el economista Shahin Vallèe, que fue miembro del gabinete de Van Rompuy, («How the greek deal could destroy the euro», NYT, 28 de julio 2015). Refiriéndose a la amenaza expresada por W. Schäuble en la noche del 12 al 13 de julio , acerca de que Grecia saliera «temporalmente» del euro, Vallèe considera que la unión monetaria tal como Alemania la concibe es incompatible con lo que las élites políticas francesas pueden vender a su opinión publica y lo que esta puede aceptar. Alemania debería comprender que ,así concebida, puede formar una unión monetaria 
con Austria, los países bálticos y los del Benelux. Pero que esa unión monetaria no sería políticamente estable con Francia y el resto de Europa.

Joschka Fischer va más lejos en esta dirección y considera que «intentar utilizar el euro como un instrumento de reeducación económica del sur de Europa, será un error peligroso, y no solamente en el caso de Grecia». No es el único alemán que piensa así; por ejemplo Henrik Enderlein, director del Instituto Jacques Delors en Berlín considera que «en la gestión de la crisis del euro se han cometido demasiados errores». Y europeístas convencidos reconocen que el euro no ha cumplido sus promesas. Así, Agnes Benassy-Quere del Consejo de Análisis Económico de Francia declara que «el euro de Maastricht no ha funcionado», y Jean Pisani-Ferry , Presidente de France-Strategy y antiguo director de Bruegel en su articulo «Can the euro be repaired?» (accesible en Project Syndicate) reconoce que «si fuésemos a hacerlo otra vez, tendríamos que hacerlo de otra manera», o que «los ciudadanos europeos se preguntan porque comparten una misma moneda, cual es el sentido del euro y si se pueden poner de acuerdo para que sea un instrumento de prosperidad compartida».

Este tipo de cuestiones se han evitado porque el coste de una ruptura se estima como demasiado elevado para que la hipótesis valiese la pena de simplemente plantearse. Pero éste es un argumento que cada vez parece más insuficiente para evitar plantearse los problemas de fondo.

Es evidente que con el euro las economías europeas, en vez de converger, han divergido más que nunca. Y que en vez de crear la confianza mutua que impulsara la unión política ha creado una nueva división y una mayor desconfianza entre el norte y el sur de Europa. En el euro, el método Monnet de los pequeños pasos, que hasta entonces fue un motor eficaz de la construcción europea, no ha funcionado. Desde 1999 hasta el 20010, no se construyeron ninguna de las instituciones necesarias al buen funcionamiento del euro. En los trabajos de la Convención quedó claro que no había ninguna voluntad de hacerlo. Y solo lo hicimos cuando las urgencias de la crisis lo hicieron imprescindible.

El aumento de los euroescépticos es debido a que en algunos países éstos comprenden mejor las preocupaciones de una parte importante de la población. Pero ello no permite saber qué hubiera ocurrido sin el euro. Probablemente los europeos pesaríamos todavía menos a nivel mundial. Quizás hubiéramos añadido a los problemas del dumping social y fiscal, el del dumping monetario y una mayor inestabilidad financiera. Puede que nuestras exportaciones no se hubiesen visto penalizadas por una moneda tan fuerte como lo ha sido el euro, aunque eso parece que es ya un problema superado. Y muy probablemente los tipos de interés no hubieran sido tan bajos como lo han sido hasta la crisis, y que sin el euro ahora volverían a subir a niveles muy perjudiciales para la recuperación. 
Pero todas estas consideraciones contrafactuales son un tanto inútiles porque la Historia no se rebobina y lo realmente importante es como optimizar el futuro a partir de este presente y no de cualesquiera otros que pudiésemos imaginar. Y eso exige hacer balance de lo ocurrido y repartir sobre bases más sólidas. Lo que a su vez exige ponerse de acuerdo sobre las verdaderas causas de la crisis, lo que está lejos de ser una realidad ni entre los economistas ni entre los responsables políticos.

Lo que a estas alturas debería ya estar claro es que no se puede pretender construir una unión monetaria con libertad de movimiento de los factores de producción y al mismo tiempo negarse a disponer de los mecanismos que permiten prevenir y corregir los desequilibrios que esos movimientos producen y hacer frente a situaciones de excepción que pueden afectar a uno de los miembros de la unión.

Por ejemplo, muchos jóvenes españoles, los más preparados, han emigrado de un país con altos niveles de paro y pocas oportunidades de empleo para sus capacidades, hacia una Alemania que sufría una penuria de mano de obra cualificada. En abstracto es algo que no puede considerarse negativo, porque uno de los objetivos de la UE es impulsar y facilitar la movilidad de la mano de obra. Pero si este movimiento continua y se acentúa, España perderá a sus jóvenes diplomados, que no contribuirán a su crecimiento ni a pagar las pensiones de los mayores, mientras que el país ha soportado el coste de su formación. Una situación insostenible económica y socialmente en el medio plazo.

En otras uniones monetarias, estos desequilibrios también se producen, pero existen impuestos a nivel de la federación y trasferencias de recursos a través del presupuesto federal que contribuyen a corregir estos desequilibrios. Es lo que ocurre en los EE. UU y en la propia RFA, pero no en la eurozona.

La crisis en la que todavía estamos inmersos nos ha puesto en evidencia que la unión monetaria que los europeos concebimos hace ya más de 20 años en respuesta a la reunificación alemana, estaba mal concebida y que hay que seguir consolidándola como hemos empezado a hacerlo creando algunas de las instituciones que más dramáticamente hacían falta y rompiendo en la práctica con algunos de los tabúes que al principio paralizaron las soluciones.

No es tarde para salvar el euro. Pero tampoco nos sobra el tiempo. Lo haremos si los europeos, o algunos de ellos, quieren de verdad unir sus destinos y sus líderes son capaces de hacerlo entender a sus opiniones públicas. ¿Qué queremos realmente que sea el euro? ¿Nos conformamos con un sistema de tipos de cambio super-fijos, con un gobierno intergubernamental tipo Eurogrupo? ¿O construir un sistema federal en el que un presupuesto central asegure el equilibrio del conjunto y un mínimo de solidaridad? 
Eso es lo que implica la apelación a «más Europa». Pero lo difícil es pasar de las musas al teatro y escribir un guión aceptable para todos los actores en el que de una forma u otra una mayor dosis de solidaridad institucionalizada y automática será imprescindible. Sin ella, la zona euro acabará explotando de forma más o menos violenta, por la fatiga de los ciudadanos o la desconfianza de los mercados

En medio de estos acontecimientos de vertiginoso dinamismo y no pocas veces de profundo dramatismo, de enorme complejidad e incertidumbre, Cuadernos Europeos de Deusto dedica su n ${ }^{\circ} 54$ a «Europa: impacto de la crisis, salidas y horizontes» con una parte politológica y otra económica.

El artículo de Nicolás Mariscal enfatiza el ambiente y la interacción globalización-Unión Europea que la paradoja de Castells expresó tan acertadamente: «la integración europea es, al mismo tiempo, una reacción al proceso de globalización y su expresión más avanzada». No pretende analizar la realidad de la globalización, ni de la Unión Europea, ni de su relación de amplitud, complejidad y dinamismo casi insondables, sino ofrecer algunos elementos conceptuales, teóricos y metodológicos de una pluralidad de autores a fin de proseguir el trascendental debate. Termina presentando varias estrategias europeas globales que se abren al futuro.

Iñigo Bullaín en «El proceso de oligarquización europeo. De la utopía federal a una distopía social y democrática» analiza en profundidad y desvela críticamente algunos de los efectos del proceso europeo y sus derivas antisociales y antidemocráticas. En la actual crisis de legitimidad europea constata la elusión de la federalización y ante el peligro de la deriva neoliberal para la integración europea aboga por un cambio de paradigma en el que más Europa sea sinónimo de mayor cohesión social y de más democracia.

Ángel Berges y Emilio Ontiveros abordan en el artículo «La Unión Bancaria (UB): Nuevo marco competitivo para la banca española y europea» la forma en que el proyecto de Unión Bancaria de Europa es producto de la intensidad adquirida por la crisis financiera y económica. Al acabar estableciéndose un círculo vicioso entre el deterioro de los activos bancarios y la deuda pública de algunos países miembros de la eurozona, particularmente intenso hasta julio de 2012, las autoridades europeas iban a verse obligadas a superar una de las limitaciones originales de la Unión Monetaria. En este artículo se analiza la génesis del proyecto de UB, su estructura así como el sistema bancario resultante, con especial atención a la dinámica de concentración sectorial.

Por su parte, Rafael Muñoz de Bustillo nos traslada un artículo titulado: «Crisis, post-crisis y Estado de Bienestar: ¿Hacia dónde transita el Modelo Social Europeo?». En él analiza las consecuencias que sobre el Estado del Bienestar en Europa ha tenido la crisis económica y la gestión de 
la misma impulsada desde las autoridades gubernamentales y comunitarias. La lógica de los ajustes parece culminar unos ataques que con mayor o menor intensidad se venían produciendo desde décadas.

En cuanto al artículo de Francisco Rodríguez, «Las crisis trastocan el inmovilismo y ortodoxia del Banco Central Europeo», se centra en analizar cómo la sucesión de crisis, desde 2008 , ha puesto a prueba la capacidad de la política monetaria para responder a las mismas. El BCE, preso de condicionantes ideológicos, ha actuado con retraso y sólo ha decidido apelar a medidas no convencionales cuando ha percibido que los riesgos de deflación eran crecientes y que la zona euro amenazaba con adentrarse en una nueva recesión debido a los errores de política económica cometidos y a las nuevas incertidumbres internacionales. Sin embargo, no parece que la política monetaria pueda resolver por sí sola los problemas de crecimiento de la zona euro.

El n. ${ }^{\circ} 54$ de Cuadernos Europeos incluye también otros tres estudios: Carlos Espaliú reflexiona sobre la participación de los individuos en la creación del derecho europeo mediante la Iniciativa Ciudadana Europea; Jérémie Houet presenta «Acciones de oro y patriotismo económico: enfoque nacional, desarrollo europeo»; y Ana Novikova nos abre a la vecindad europea con un trabajo acerca de los discursos en y sobre Ucrania.

Este número de Cuadernos Europeos de Deusto concluye, como viene siendo habitual, con los comentarios de David Ordóñez Solís a la jurisprudencia reciente del Tribunal de Justicia de la Unión Europea y con una Crónica de la actualidad institucional y económica de España en el marco de la Unión Europea elaborada por Beatriz Iñarritu.

Iosep Borrell 


\section{Derechos de autor (Copyright)}

Los derechos de autor de esta publicación pertenecen a la editorial Universidad de Deusto. El acceso al contenido digital de cualquier número de Cuadernos Europeos de Deusto (CED) es gratuito, transcurridos 6 meses desde su publicación. Los trabajos podrán descargarse, copiar y difundir, sin fines comerciales y según lo previsto por la ley. Así mismo, los trabajos editados en CED pueden ser publicados con posterioridad en otros medios o revistas, siempre que el autor indique con claridad y en la primera nota a pie de página que el trabajo se publicó por primera vez en CED, con indicación del número, año, páginas y DOI (si procede). 